\title{
Herbst rods uncovered: benefits and limitations
}

\author{
Michel AMORIC
}

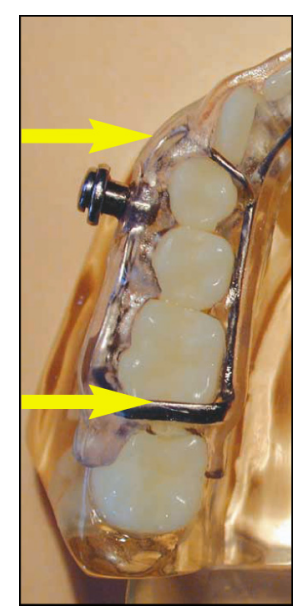

\section{ABSTRACT}

Uncovering the Herbst rods can make wearing the appliance more comfortable for some patients. On the other hand there can be some disadvantages to this procedure:

- it might make cementing or bonding of the appliance, in case of poor cooperation, impossible;

- it might interfere with vertical growth depending on the bearing points;

- it might disturb occlusion because of the wires that would pass over the occlusal surfaces;

- it might impair the retention of the appliance during the period when temporary teeth are being shed.

This article will also present other modifications, relating to the pivots, to the elimination of the anterior portion of the device, and to the use of springs on the branches. Their respective benefits and limitations will also be presented and discussed.

\section{KEYWORDS}

Herbst rods or connecting arms

Splint

Thermoforming

Uncovering

Comfort

Pivots. 


\section{1 - INTRODUCTION}

Today Herbst rods ${ }^{12-13}$ are employed in a variety of ways, either soldered to bands or pedodontic caps or attached to a thermoformed splint ${ }^{15,16}$. According to Sanden, Pancherz and Hansen ${ }^{21}$ when rods are soldered there is always a great risk of breakage occurring. While rods incorporated in remobable splints are more robust (fig. 1), they can only work when patients are compliant. However, when patients do not wear their appliances enough, the orthodontist can cement them and hope for improved

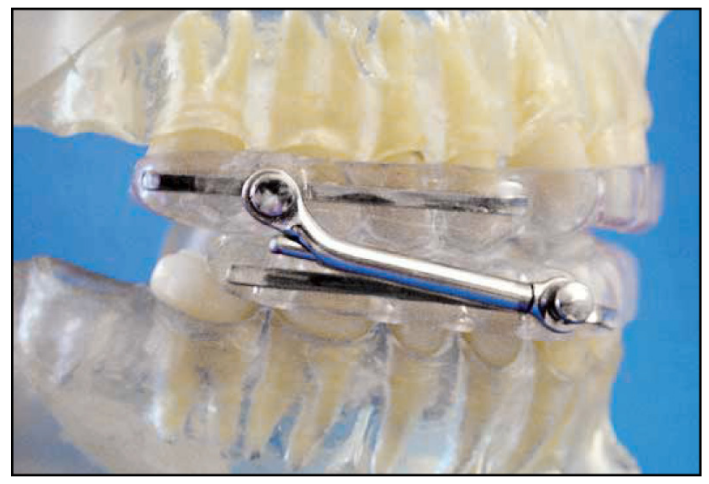

cooperation from the patient at a later time. But there is, unfortunately, no such possibility when uncovered splints are being used. By using Herbst connecting rods in association with splints ${ }^{16-21}$ orthodontists can control the direction of vertical growth14 by their placement of occlusal contacts. For example, a stop placed in the molar region can provoke the mandible to develop in an anterior rotational movement (fig. 2). Placed in the molar, conversely, stops will encourage posterior rotation ${ }^{1-10}$.
Figure 1

Herbst rods on complete splints.

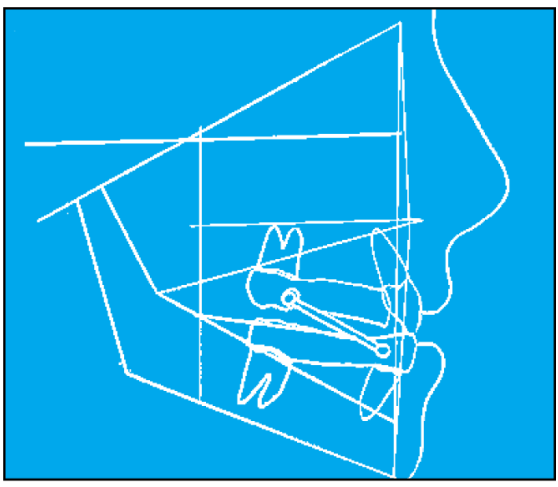

a

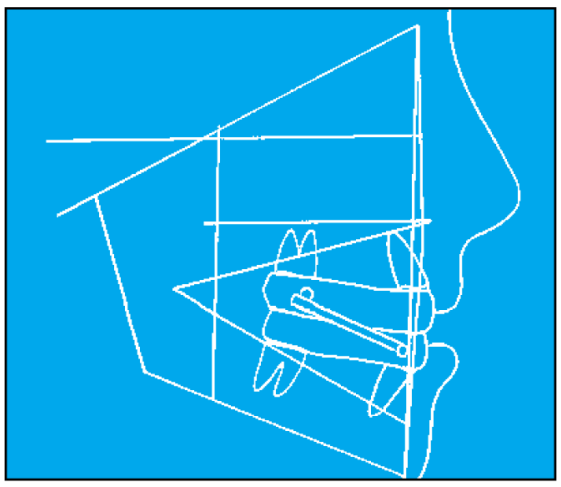

b

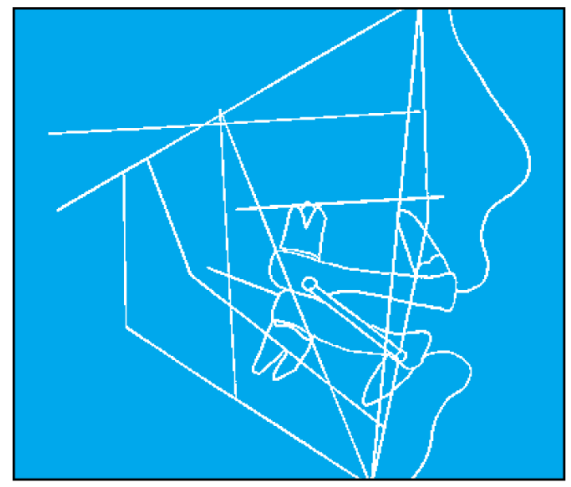

c

Figures 2 a to $c$

Adjustment of the occlusal bearing points of splints during the active phase of treatment: from left to right: adjustment for deep bite / posterior rotation, normal-bite / equilibrated occlusion open-bite / anterior rotation. 


\section{2 - REMOVING THE OCCLUSAL COVERAGE}

It was Schangé22 who provided us, in 1857, with the first description of uncovered splints. Although this type of splint is more comfortable for some patients to wear, we should not lose sight of its disadvantages:

- it may cause premature occlusal contacts from wires crossing occlusal services (fig. 3);

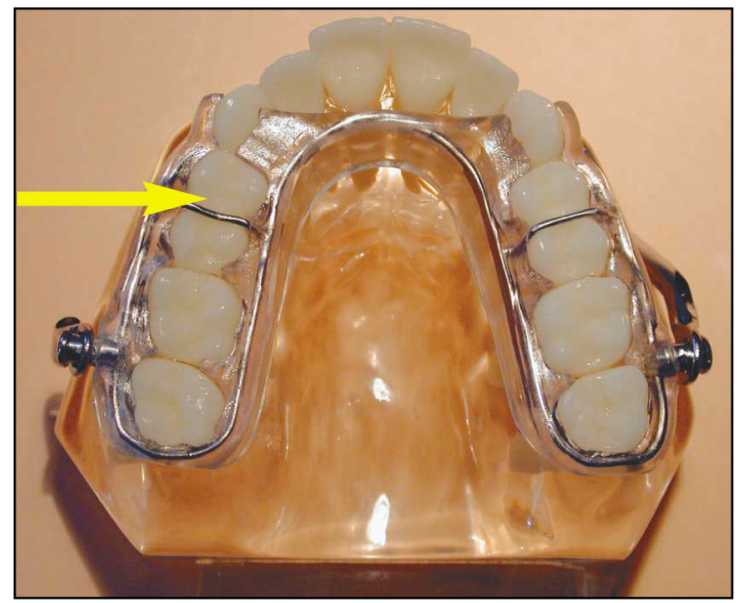

a
- it might be less retentive during the period when temporary teeth are being shed, a time when orthopedic responses are often the most stable ${ }^{17}$.

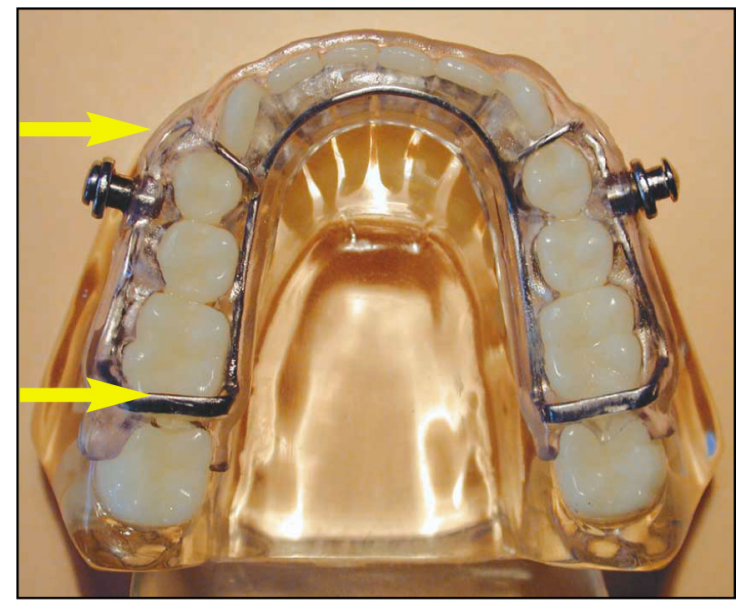

b

Figures $3 a$ and $b$

The trans-occlusal reinforcement wires of the unencumbered splints provoke uncontrollable iatrogenic premature contacts.

\section{3 - REDUCTION IN THE PROMINENCE OF THE LOWER PIVOTS}

In order to improve the patient's comfort, some makers of the Herbst rods offer screw heads whose contours are considerably reduced (fig. 4).

Others provide silicone caps that can be used to cover the screws (fig. $5 \mathrm{a}$ and $\mathrm{b}$ ). However, while seeming it first to provide the desired the relief they have the opposite effect by increasing the size of the pivot.
Ampen ${ }^{11}$ proposed a thoughtful solution by replacing the lower pivot with pre-shaped wire. Vela-Hernandez and et al. ${ }^{23}$ placed the rods in the middle of the occlusal surfaces, which completely eliminated the need for the pivots if the practitioner were able to accept an increase in vertical dimension. But a simpler solution is to move the pivot from the canine region distally from the mandibular 


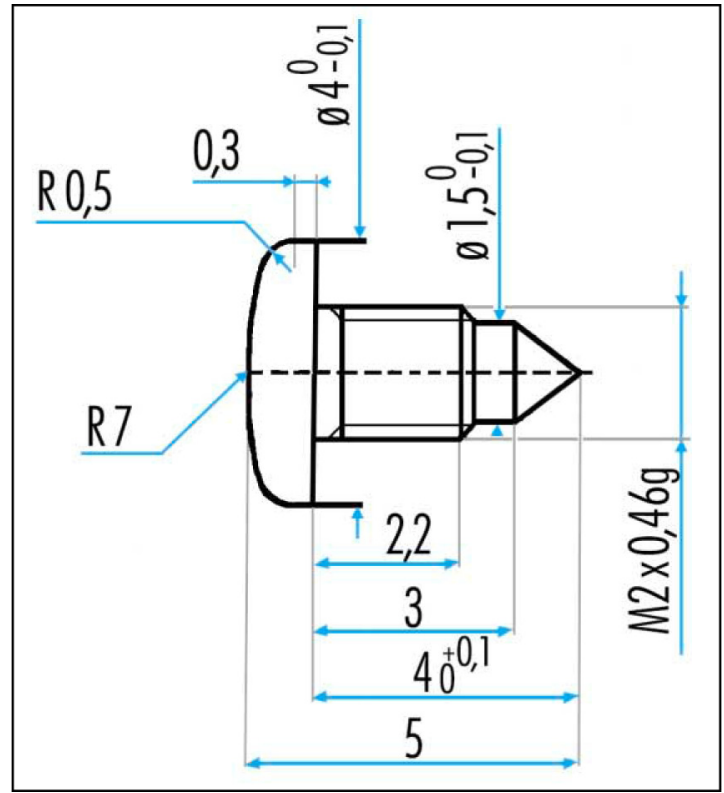

Figure 4

Plan for the fabrication of a screw with a rounded head. One can also see the point of the opposite side making a punch hole in the pivot to prevent unscrewing.
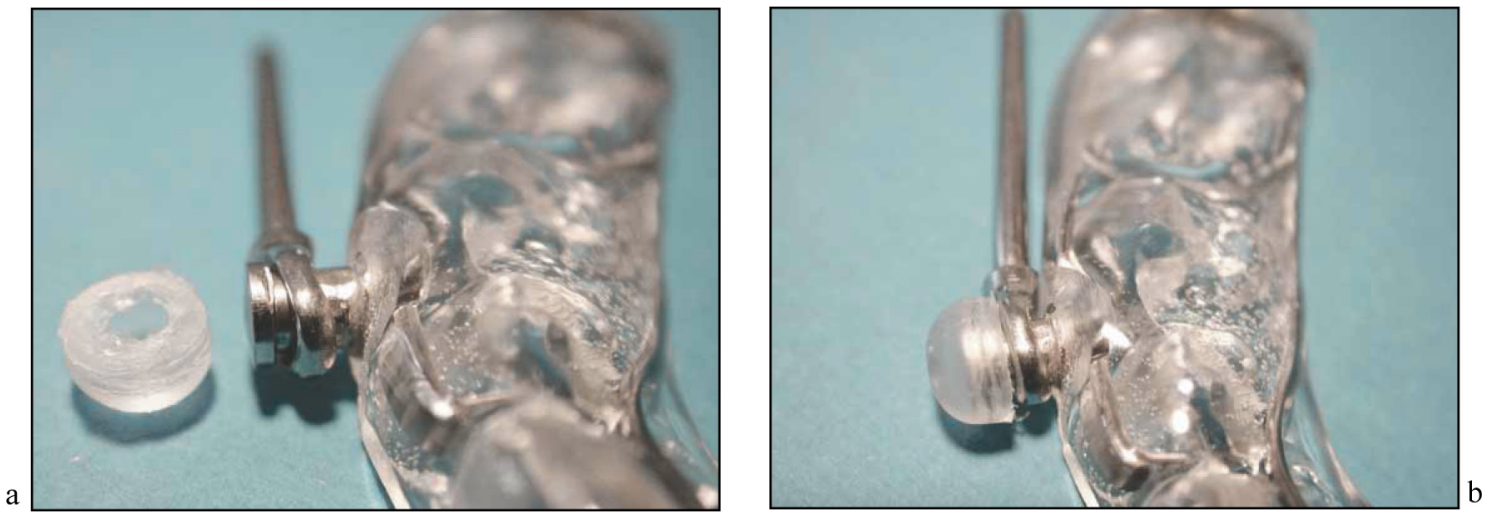

Figures $5 a$ and $b$

Silicone "protection."

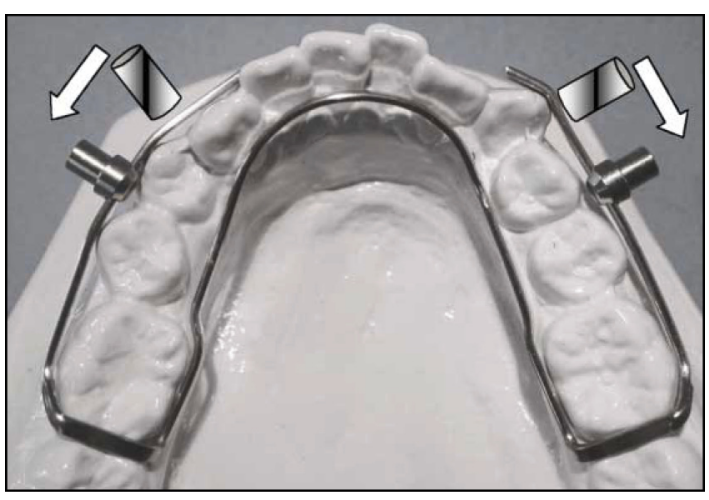

Figure 6

Distal displacement of the pivots, from a distal position to the canines to one distal to the first premolars or the first temporary molars.

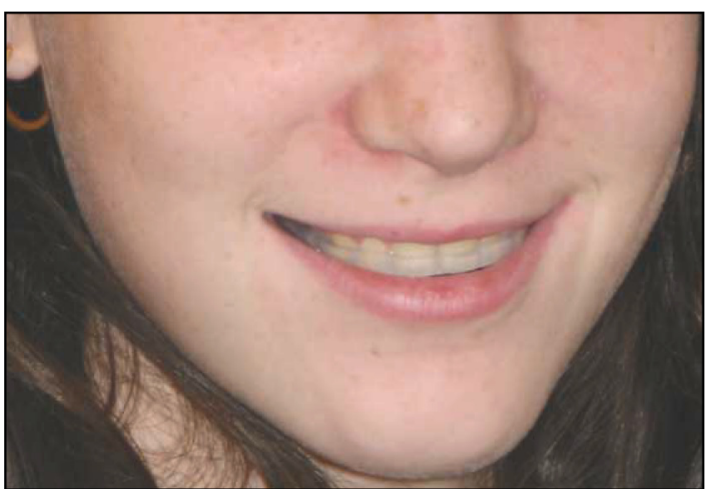

Figure 7

View of a female patient wearing splints whose mandibular pivots have been set between the first and second premolars. 
canine and first premolar area to the region of the first and second premo- lars (fig. 6), so that the pivots won't impinge at all on the lips (fig. 7).

\section{4 - REMOVAL OF THE MAXILLARY ANTERIOR PORTION OF THE APPLIANCE}

Orthodontists should not decide to remove the anterior portion of the maxillary portion of the appliance for esthetic reasons if that would diminish its therapeutic effectiveness. But removing the anterior part of the splint so that the posterior segments can be moved distally without the appliance's provoking any movement of the upper incisors and canines, for example can be an excellent choice, in treatment of Class II, division 2 cases. But for retraction of the entire arch, a full splint is still the best solution.

\section{5 - PLACEMENT OF A SPRING AROUND THE ROD ARM}

The therapeutic action of mandibular advancement appliances results from the mandible being held forcibly in a more anterior position... At rest the Herbst rods generate a force of about $200 \mathrm{gr}$ on the entire arch no matter what the extent of the forward

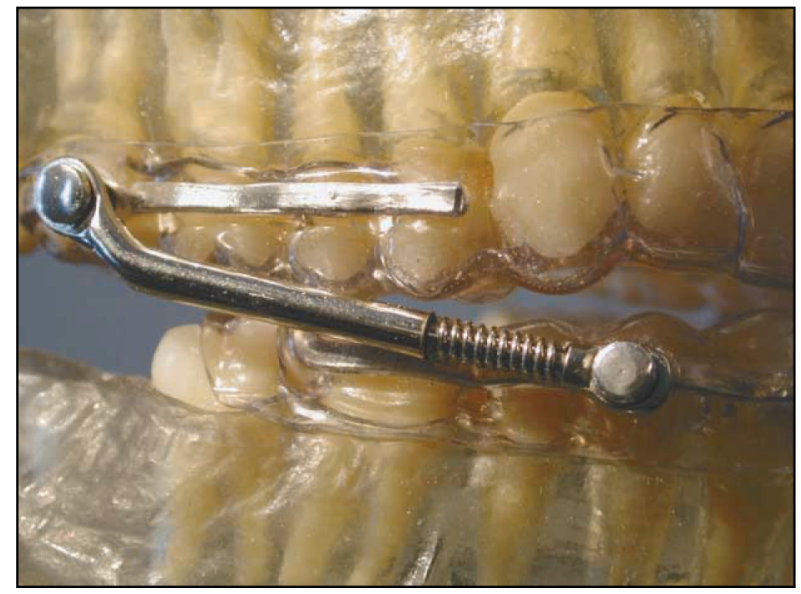

Figure 8

Insertion of an open spiral spring around the axis of the rod... propulsion is, with or without springs (fig. 8 and 9). Placing a spring around the rods would not help as it does in the similar mechanics of the "Jasper Jumper" or the "turbo spring", nor would it increase the patient's comfort.

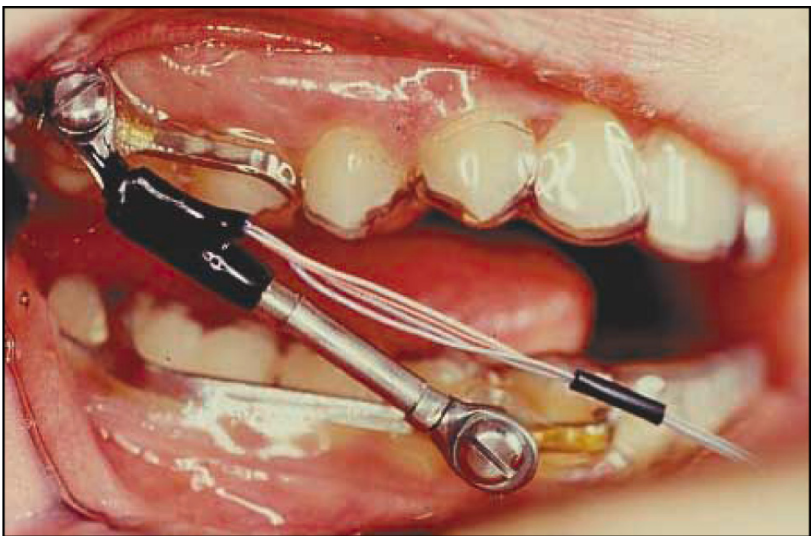

Figure 9

Measurement of the force registered electro-dynamically with the teeth closed and the teeth apart. 


\section{CONCLUSION}

As they can with any appliance, orthodontists can adapt the Herbst rods associated with thermoformed splints in accordance with whatever ends their personal preferences, needs, and inspirations suggest. But they should not let their best intentions to improve the patient's comfort decrease the therapeutic efficacy of the appliance. They should use unen- cumbered splints or splints with anterior portions remo- ved only for certain specific problems and under specified conditions. Placing wires occlusally is not the best way to control physiological eruption of teeth. In addition, not being able to use a mandibular advancement appliance during the time a patient is shedding temporary teeth could be a handicap.

\section{REFERENCES}

1. Amoric M. Le propulseur amovible thermoformé à bielles de Herbst. Rev Orthop Dento Faciale 1989;23:493-501.

2. Amoric M. Thermoformed Orthodontic appliances. J Clin Orthod.1990;24:351-9.

3. Amoric M. Gouttières thermoformées orthopédiques. Act Odonto Stomatol 1990;172:675-95.

4. Amoric M. Effets thérapeutiques comparatifs entre monoblocs, force extra-buccale et bielles de Herbst sur gouttières thermoformées. Orthod Fr 1993;64:181-5.

5. Amoric M. Gouttières orthodontiques et orthopédiques thermoformées. Monographie. Editions S.I.D, 1993, Paris.

6. Amoric M. Thermoformed Herbst Appliance. J Clin Orthod 1995;29:173.

7. Amoric M. Techniques de fabrication des appareils amovibles orthodontiques et orthopédiques. Enc Méd Chir 1998:23-380-D-10.

8. Amoric M. Numéro spécial, bielles de Herbst. Rev Orthop Dento Faciale 1999;33:325459.

9. Amoric M. Gouttières orthopédiques \& orthodontiques, monographie, Editions SID, 2002, Paris.

10. Amoric M. Thermoformed Orthodontic appliances. J Clin Orthod 1990;24:351-9.

11. Ampen $P$, Guyot $P$. Forme particulière de la structure métallique de la gouttière inférieure de l'appareil de Herbst. Rev Orthop Dento Faciale 1997;31(3):349-52.

12. Herbst E. Eine neue schiene zum vorschieben des unterkiefers. Zeitschrift für zahnärztliche orthopädie. Berlin, 1909 (Bd III); n 10:410-3.

13. Herbst E. Dreissigjahrige Erfahrungen mit dem retentions. Zahnärztl (Rundschau) 1934;43:1515-24.

14. Kambara T. Dentofacial hanges produced by extraoral forward force in Macaca irus. Am J Orthod 1977;74:249-77.

15. Lous I. Treatment of TMJ Syndrome by pivots. J Prosthet Dent 1978;40:179-83.

16. McNamara JA, Howe R. Fabrication of the acrylic splint Herbst appliance. Am J Orthod Dentofacial Orthop 1988;94:142-9.

17. Pancherz H. Relapse after activator treatment. Am J Orthod 1977;72:499-511.

18. Pancherz $\mathrm{H}$. Treatment of Class II malocclusion by jumping the bite with the herbst appliance. Am J Orthod 1979;76:423-42. 
19. Pancherz H, Malmgren D, Hagg U, Omblus J, Hansen K. Class II correction in Herbst and Bass therapy. Eur J Orthod 1989;11:17-30.

20. Ruff S, Pancherz H. Temporomandibular joint remodeling in adolescents and young adults during Herbst treatment. Am J Orthod Dentofacial Orthop 1999;115:607-18.

21. Sanden E, Pancherz H, Hansen K. Complications during Herbst appliance treatment. J Clin Orthod 2004;38:130-3.

22. Schangé JMA. Précis sur le redressement des dents ou exposé des moyens rationnels de prévenir et de corriger les déviations des dents, suivi de quelques réflexions sur les obturateurs du palais, Editions Béchet Labé Paris 1842:145-76.

23. Vela-Hernandez A, Lasagabaster-Latorre F, Ponce de Leon JM, Rico-Lillo I. Clinical management of the Herbst Occlusal Hinge appliance. J Clin Orthod. 2004;38:590-9. 